\title{
Clínica da atividade em uma via deleuziana: por uma psicologia do trabalho
}

\section{Clinic of activity's in the Deleuze's way: for a work psychology}

\begin{abstract}
Resumo: Este texto apresenta a construção de um caminho conceitual-metolológico para nossas investigações em análise do trabalho. Buscando alianças potentes, ousamos fazer conexões entre os instrumentos da Clínica da Atividade para pensar o real do trabalho e as ferramentas analíticas formuladas por Gilles Deleuze, pois acreditamos que seus postulados se atravessam, nos ajudando a pensar a questão da atividade e da subjetividade no trabalho numa direção em que não basta protestar, mas afirmar seu movimento. Essa aliança nos auxilia na criação de estratégias de afirmação da potência do trabalho como capacidade da vida em diferir, em produzir o novo, em criar sujeitos e mundos. Afirmamos uma Psicologia do Trabalho que, construída na interlocução com a Clínica da Atividade, busca cartografar os processos de trabalho; construir novos sentidos; o que não significa descrever-catalogar, mas intervir-transformar. Intervenções que tenham como princípio ético-político o estudo da atividade visando a sua transformação, o que envolve mobilização subjetiva. Proposta de uma clínica como um fazer político/coletivo.

Palavras-chaves: Clínica da Atividade. Ética-EstéticaPolítica. Psicologia do Trabalho.
\end{abstract}

Abstract: This text presents the construction of a conceptual-methodological route for our investigations on analysis of the work. Seeking for powerful alliances, we dare making connections between Clinic of Activity's instruments of thinking real work and the analytical tools of Gilles Deleuze, because we believe that both postulates dialogue when helping us think the issue of activity and subjectivity at work in a direction where it is not enough to protest, but to prioritize their movement. This alliance helps us to create strategies for assuring work's power and life's capacity of becoming different, of producing new ways, creating new subjects and worlds. We assure a Psychology of Work that, built on dialogue with the Clinic of Activity, seeks for carthographying work processes; for building new meanings; what does not mean to describe-catalogue, but intervene-transform. Interventions that have as ethical principle the study of activity aiming its transformation, which involves subjective mobilization. Proposal for a political/collective clinic.

Keywords: Clinic of Activity. Ethics-Aesthetics-Politics. Work Psychology

BARROS, Maria Elizabeth Barros de; LOUZADA, Ana Paula VASCONCELLOS, Dani. Clínica da atividade em uma via deleuziana: por uma psicologia do trabalho. Informática na educação: teoria \& prática. Porto Alegre, v.11, n.1, p. 1427, jan./jun. 2008

\author{
Maria Elizabeth Barros de Barros \\ Universidade Federal do Espírito Santo \\ Ana Paula Louzada \\ Faculdade Salesiana de Vitória \\ Dani Vasconcellos \\ Universidade Federal do Espírito Santo
}

\section{Provocações a um exercício de pensamento}

0

presente artigo é uma tentativa de delineamento teórico-metolológico a partir de uma provocação. Fomos interpeladas a escrevê-lo. E aceitamos essa ousadia de bom grado. O professor e investigador Yves Clot, em um encontro com um grupo de pesquisadores brasileiros, em setembro de 2007, na Universidade Federal Fluminense, nos convocou a pensar quais os sentidos estamos atribuindo a nossas ferramentas conceituais. Como um analista do trabalho, Clot perguntou insistentemente: como vocês trabalham?

Nesse artigo, buscamos tomar o nosso trabalho de pesquisadoras a partir dessa indagação-provocação de Clot: como nós trabalhamos? Como a Clínica da Atividade tem sido ferramenta conceitual-metodológica para nossas investigações? Que tecnologias nos oferece para os trabalhos no campo da educação? Que acoplamentos traçamos entre seus instrumentos para analisar o real do trabalho e as ferramentas analíticas formuladas por Gilles Deleuze? De que modo essa aliança nos instrumentaliza para analisar o trabalho docente? Que deslocamentos produzimos? 
Assim, ousamos fazer conexões que forçam os limites da abordagem da Clínica da Atividade, pois os conceitos são vivos e é preciso reinventá-los. É nesse desafio que nos lançamos nesse artigo. Que Psicologia do Trabalho afirmamos quando operamos como profissionais antenadas com os mundos do trabalho? Que Psicologia? Que trabalho?

Para início de conversa: não identificamos trabalho com assalariamento ou emprego, mas como uma trama, um campo complexo e instável, uma rede de conexões que se produz incessantemente. Postulamos uma compreensão do trabalhar como uma atividade inventiva, criadora de normas, que transborda uma execução mecânica de tarefas, afirmando uma concepção de trabalhador que não se reduz a um autômato reprodutor de normas prescritas e técnicas de trabalho predeterminadas.

Partimos do princípio de que os trabalhadores para realizarem as tarefas definidas nos ambientes laborais, acordadas com a chefia e com os demais companheiros, elaboram, a cada situação que se coloca, o melhor modo de trabalhar, improvisam ações, criam um modo de organizar o trabalho, uma forma específica de agir, de se relacionar com os colegas e de estabelecer regras específicas na divisão de tarefas. Além disso, o trabalho é constituído por um conjunto de atividades simultâneas, que possuem características diferentes e são exercidas por trabalhadores de diversas áreas, com saberes e experiências específicas. A atividade do trabalho, portanto, é submetida a uma regulação que se efetiva entre os trabalhadores, numa dinâmica que se realiza a partir de diferentes valores.

A Clínica da Atividade é tomada por nós como uma importante aliada, uma vez que nos auxilia na criação de estratégias de afirmação da potência do trabalho como capacidade da vida em diferir, em produzir o novo, em criar sujeitos e mundos; e para tal nos apropriamos dessa abordagem, "sujando-a". Assim como os humanos "sujam" com suas marcas pessoais e coletivas as suas atividades laborais, "sujamos" as propostas de Clot, quando não repetimos apenas as suas instruções, quando delas nos apropriamos para fazer rizomar esses suportes teórico-metodológicos com a perspectiva ética-estética-política de Deleuze.

A escolha de Deleuze se fez, não só por considerá-lo um pensador instigante, que nos força a pensar, mas, principalmente, pela des- medida de sua abordagem, que arrasta o instituído para o "vazio do porvir" (MAIA, 2006). Por outro lado, percebemos que os postulados de Yves Clot, na Clínica da Atividade e de Deleuze se atravessam, e essa intercessão pode ser muito interessante no traçado de um outro modo de operar no campo da nomeada psicologia do trabalho.

O próprio Clot (2007) faz referência a Deleuze, retomando uma afirmação deleuziana: "sempre existe na organização do trabalho mecanismos para impedir o movimento" e afirma que o propósito da Clínica da Atividade é se colocar no movimento para ir além da organização do trabalho. Para Clot (2007), autores como Deleuze e Foucault nos ajudam a pensar a questão da atividade e da subjetividade no trabalho quando afirmam que não basta protestar, mas afirmar o movimento. A principal crítica que tem sido feita à organização do trabalho é, exatamente, uma forma de funcionamento que tenta impedir a passagem do vivido. Clot reafirma a importância de considerarmos os trabalhadores como protagonistas da transformação.

\section{A psicologia do trabalho: práticas adaptativas?}

Historicamente, a psicologia propiciou, no âmbito dos mundos do trabalho, a consolidação de um modelo gerencial que visava excluir o trabalhador da concepção do trabalho, na tentativa de efetuar a separação entre saber/ fazer: à gerência, planejar, e aos operários, pura "mão-de-obra", executar. Caberia à psicologia o exercício de uma adequação do trabalhador a um posto de trabalho de antemão conhecido e demarcado, como se houvesse um cargo desprovido daquele que o ocupa. Durante o século $X X$, foram desenvolvidas estratégias de recrutamento, seleção, treinamento, análise de desempenho com esse intuito.

Dessa maneira, uma psicologia adaptativa contribuiu diretamente com a Organização Científica do Trabalho, no sentido de produzir trabalhadores adaptados a um fazer parcelado, mecanizado, em uma tentativa de destituir o trabalho de sentidos outros, que não aqueles já previstos pelo planejamento do trabalho (ATHAYDE, 1999).

O trabalho tornado mecanizado exigiria um trabalhador também mecanizado em seus devidos códigos profissionais, em suas ações 
ensaiadas/treinadas, em sua cognição minuciosamente separada de valores, sentimentos ou outros atravessamentos considerados perigosamente perturbadores de um curso antevisto da atividade profissional.

Os trabalhadores, como engrenagens, deveriam corresponder automaticamente aos comandos das chefias. Esse trabalho automatizado e padronizado, "sem conteúdo subjetivo", ou sem participação efetiva do trabalhador, sem seus afetos e cognição, nunca existiu de fato. Nenhum trabalho por mais simples que seja, encontra no corpo do "executante" um autômato. À organização formal, os trabalhadores respondem com uma contra-organização, ao mesmo tempo resistência (no sentido afirmativo e negativo do termo) e contraditoriamente com a viabilização das atividades prescritas (ATHAYDE, 1999).

Uma psicologia adaptativa, dirigida à prescrição e ao ajustamento, pretensamente isenta dos processos de históricos e políticos, não se abre ao inusitado do trabalho, aos sentimentos que ele provoca e mobiliza, aos sentidos que cada sujeito atribui ao seu trabalho. Uma psicologia que não escuta a pergunta: qual a função do trabalho para aquele que o exerce?

Certamente, não são tais práticas adaptativas que desejamos. Faz-se urgente, a viabilização de uma psicologia do trabalho, diretamente comprometida com a análise dos processos de produção de saúde/trabalhador; uma outra via orientada para a afirmação e expansão da vida.

Nesse sentido, vários estudos, com diferentes abordagens teóricas e metodológicas, vêm sendo desenvolvidos, principalmente a partir dos anos 80/90, na França, com o intuito de produzir ferramentas teórico-metodológicas para a análise do trabalho. Nessa direção, podem ser citados: a Ergonomia Francesa, a Ergologia, a Psicodinâmica do Trabalho, e mais recentemente, a Clínica da Atividade. Essas abordagens não se restringem à psicologia, não são específicas ao seu "domínio". Envolvem diferentes áreas, instrumentaliza engenheiros, administradores, enfermeiros, médicos, entre outros. Para a psicologia ressoam como possibilidades de reinvenção de nossas práticas. Nesse artigo, especificamente, estamos interessadas em afirmar o quanto a Clínica da Atividade, entrecortada pelo viés analítico deleuziano, nos potencializa a tecer um novo modo de intervir nas situações de trabaIho, destacando as tecnologias que nos oferece para uma análise do trabalho docente.

\section{Clínica-política: trabalho e subjetividade}

Usualmente, a palavra clínica em psicologia traz um suposto cenário de neutralidade, um palco para os problemas psíquicos, uma composição intimista a meia luz para dar vazão aos dramas individuais. Pensar o trabaIho como uma clínica, e uma clínica subjetiva, rompe com essa composição. Esse lugar quase sagrado, intocável, sem cheiro das ruas, das massas é estilhaçado, fazendo-se em mil pedaços, dando voz a uma clínica como produção da diferença, como desabitando o solo dos conflitos "intra-psíquicos", tomando a clínica como política, entendendo a política como expressão de forças coletivas que, ao permear a vida, produzem os humanos dessa ou daquela maneira (COIMBRA, 2005, p. 42).

Ao interrogarmos essa dimensão política, o lugar em que o psicólogo se coloca e é colocado, ou seja, como aquele autorizado a lidar com a dimensão subjetiva do trabalho, nos jogamos numa viagem cartográfica, numa experimentação que busca linhas que recusam este lugar cristalizado de especialista do funcionamento dos humanos em situação de trabalho. Como recusar a esse "mandato social" que atribui ao psicólogo do trabalho controlar, docilizar, esse "fator humano", fator que indica a inviabilidade de considerar homens e muIheres como máquinas? E mais, se afirmamos a potência da vida, como investir em práticas que não nos anestesiem e nos tornem insensíveis ao que se passa nos mundos do trabalho, insensíveis ao que nos dizem aqueles que se "sujam" cotidianamente nos ambientes laborais. Como nos diz Maia (2006): "tudo uma urgente questão de implicação, pois não fazer escolhas, se deixar levar pelos acontecimentos, já é ter escolhido".

Questionamos os especialismos, portanto, pela relação interceptora que estabelecem quando tentam silenciar a voz do trabalhador, quando perseguem o enfraquecimento da força instituinte do saber dos trabalhadores, mesmo quando isso não se coloca de forma explícita, mas pela maneira de conduzir as intervenções. Numa outra direção, uma ação intercessora, e não interceptora (MAIA, 2006), 
afirma o outro na sua diferença, os processos de singularização, de tal forma que não seja apenas o critério científico o que vai interferir ou decidir os impasses presentes na complexidade dos mundos do trabalho.

A direção que indicamos para uma Psicologia construída na interlocução com a Clínica da Atividade é, assim, a de cartografar os processos de trabalho; construir novos sentidos que possam se constituir como linhas que fogem do modelo hegemônico proposto para os profissionais Psi, seu mandato social, criando outras direções e, nessa construção, efetuar uma cartografia com os trabalhadores acerca do trabalhar.

Para Deleuze (1997), cartografar, traçar mapas, é delinear modos de expressão ocupados por afetos, por constelações afetivas, por devires. Na analise dos processos do trabaIho, trata-se de deixar de tomar as atividades como expressão de uma subjetividade identitária ou uma sujeição a priori, já conhecida, para ousar cartografar novas configurações afetivas, tomar um trabalho como possibilidade de expressão de uma subjetividade em sua diferença. Cartografia, então, como um caminho metodológico que se constitui como uma descrição funcional, o que não significa descrever-catalogar, e, sim, intervir-transformar. Processo que se constrói na medida em que se põe em marcha, mapeando linhas de forças, abrindo-se para a experiência, que tem o sentido do clinamen, ou seja, de um desvio criador. Portanto, transformar para compreender, proposta de uma clínica como um fazer político/coletivo.

É nesse ponto que aceitamos o desafio que nos coloca Clot: desenhar as ferramentas que permitam um afastamento deste lugar do especialismo, partindo de uma Clínica Transversal; clínica como clinamen, de uma linhagem do materialismo epicurista e desenvolvida por Lucrécio, que diz que os átomos, em virtude do seu peso e velocidade, e não como intervenção divina, ao caírem no vazio, na sua colisão, provoca desvios que, então, engendram tudo quanto existe. As coisas e os movimentos se criam por um mecanismo sem qualquer regra de tempo ou de lugar (ATHAYDE; FIGUEIREDO, 2004).

Nessa perspectiva, entendemos que, além de uma atitude de acolhimento, expressa no inclinar-se em direção ao doente (klino), a clínica porta também esta dimensão de desvio criativo (clinamen), que faz do ato clínico uma relação intercessora, colocando-se no lugar de passagem, abrindo-se para o diferir que se produz neste encontro de corpos que, em interferência mútua, criam mundos possíveis, construídos na abertura do afetar e do se deixar ser afetado por esta experiência.

Uma clínica então que visita o outro em sua diferença, que se abre para a experiência do contemporâneo, no qual se dá o encontro, e opta por não reduzir esta experiência a um modelo predeterminado, mas que busca neste não-lugar de passagem, que é ao mesmo tempo lugar de atravessamentos múltiplos, a aposta na afirmação da potência criativa dos corpos. Clínica nunca dada de todo, sempre por ser construída, aberta à experiência (MAI A, 2006).

Partindo dessa concepção de clínica postulamos uma psicologia do trabalho como clínica do trabalho, que busca deslocar o analista para este não-lugar. Uma abordagem clínica do trabalho que produz intervenção e cria novos territórios existenciais. Em conseqüência, a análise do trabalho só se efetivará como um espaço de diálogo, de encontros, de experiência compartilhada, afirmando-se a inseparabilidade do conhecer e do fazer. Uma clínica do trabalho, portanto, que nos coloca de passagem, nos coloca entre, evitando reduzir o trabalho vivo a padrões abstratos de conhecimento e de apreensão de uma realidade já dada.

Portanto, ao adotar a expressão clínica não nos reportamos a qualquer teoria do sujeito, mas a esse caráter sempre enigmático e singular do trabalho. "Um regime de co-produção, engajando em um espaço de colaboração dos meios de trabalho/racionalidade da ação e o meio científico racionalidade/científica" (ATHAYDE; FIGUEIREDO, 2004, p. 245).

Clínica do trabalho, clínica da atividade. Atividade como algo mais do que a tarefa realizada, passível de descrição para fins de análises científicas, mas constituída, também, pelos conflitos que o trabalho vivo atualiza, realizado entre intenções concorrentes. Uma clínica que opera na interlocução com diferentes regimes de produção de saberes. Assim sendo, a atividade exige a mobilização física e psíquica do trabalhador num meio em constante variação. Para realizar o seu trabalho, os humanos fazem escolhas, tomam decisões, improvisam, o que só se efetiva com desvios criativos que viabilizam a realização da tare- 
fa prescrita. Dessa forma, concordamos com Maia (2006) quando afirma que a

[...] atividade, com seus desvios criativos convocam a fábrica da subjetividade a entrar em ação, como sendo o corpo invisível do trabalho, [...] que a exploração atual incide sobre este corpo invisível, controlando seu potencial inventivo e, se entendo o trabalho como uma produção desejante, entre outras, processada pelas corporizações, nome que dou aos agenciamentos, a exploração é a constante tentativa da captura do desejo, impedindo-o de singularizar, bloqueando sua natureza revolucionária (p. 200).

Segundo CLOT, o trabalho não é uma atividade entre outras, pois ele exerce uma função psicológica específica. O trabalho é entendido como uma atividade dirigida, pois é dirigida pelo sujeito, para o objeto e para a atividade dos outros (2006, p. 78).

Para a Clínica da Atividade, temos que considerar a subjetividade como um ponto necessário para se olhar o trabalho, pois nenhuma atividade é organizada somente pelas prescrições; ela é organizada por aqueles que o realizam. Há necessariamente em cada ato de trabalho, um viés coletivo.

Não basta, assim, afirmar que o trabalho é atravessado pela subjetividade, mas que modos de subjetivação estão em curso. Sem dúvida, o trabalho no capitalismo é lugar de sujeição, de individualização, de exploração, de marcações identitárias. A isso a psicologia adaptativa correspondeu e corroborou. No entanto, as atividades laborais também escapam à sujeição, escorrem entre as mãos do poder instituído, fazem-se como um meio de diferir, de resistir às cooptações.

De acordo com Clot (2007), importa interrogar o sujeito sobre sua atividade, confrontando-o com seu fazer, reportando aos modos pelos quais realiza tais ações e deixa de realizar tantas outras. Essa interrogação é uma intervenção clínica: de que modo aquele sujeito, no exercício de seu ofício, em meio a um conjunto de regras e valores, assume fazer de tal modo e não de outro, exige uma análise que remete a fazeres coletivos. Desse modo, analisar o trabalho, analisar um fazer, implica em cartografar, em acompanhar seus contornos, acompanhar seus desenhos e movimentos, explorar seus meios e trajetos.

Postulamos, dessa forma, que o psicólogo do trabalho realize intervenções, na qual a clínica está sempre por ser construída. Interven- ções que tenham como princípio ético-político o estudo da atividade visando à sua transformação, o que envolve mobilização subjetiva. Clínica nesse sentido, reafirmamos, refere-se a uma dimensão que atravessa os sujeitos em ato, e é marcada, necessariamente, por um fazer coletivo. Trata-se de afirmar a importância da subjetividade, seu lugar - ou seu não-lugar, habitando o entre, o meio - nas análises do trabalho. Afirmamos a impossibilidade de um fazer sem corpo, sem afetos. Mas isso não remete de forma alguma a uma clínica privatista ou de cuidados individualizados. Nunca se trabalha só. A solidão, ser deixado apenas diante de si nas atividades laborais, é vivida como sofrimento.

\section{Dimensões da atividade: planos molar e molecular}

Diremos que o conceito de trabalho é entendido como uma atividade histórica, construída e reconstruída na e em cada situação com a qual o trabalhador se defronta. A atividade é sempre mais do que um simples gesto realizado que observamos diretamente; envolve, também, "além do que foi realizado, o que não foi feito, o que é feito para não fazer, o que se gostaria de fazer e o que deveria ser feito" (CLOT, 2006, p. 28).

Entre o que está prescrito pela organização do trabalho e o que é efetivamente realizado, há sempre um deslocamento, uma (re) criação, o que viabiliza a realização da tarefa. Os trabalhadores, coletivamente, são capazes de inovações, de produzir regras, não se submetendo inteiramente a elas. Trata-se de uma negociação permanente da atividade, negociação com as normas prescritas, com os outros trabalhadores, com valores, existe sempre, está marcada por situações conflituosas, mas está presente mesmo nas situações de "trabalho dominado" (SELLIGMAN-SILVA, 1994).

Toda atividade é um jogo acionado pelos saberes e estratégias acionados pelo sujeito em ato; ao mesmo tempo, esse ato é interpessoal pelo fato de ser uma atividade dirigida para os outros, pois "[...] sem destinatário a atividade perde o seu sentido" (CLOT; LEPLAT, 2005, p. 310). Para Clot (1999), esse processo, coletivo e singular, é o que sustenta o sentido do trabalho para o trabalhador. Quando os limites são tantos que o desenvolvimento coletivo e singular fica impedido, os custos para o 
processo de saúde e doença são altos, podendo entrar em cena o sofrimento patogênico.

Entretanto, essas duas dimensões são atravessadas por uma organização do trabalho, que independe dos atos individuais e interpessoais. Nenhuma atividade é programada apenas em termos das necessidades ou decisões daquele que a exerce, nem mesmo em função de seus pares. Há na atividade, uma dimensão "esfriada", "endurecida" por normas, valores sedimentados em um aspecto impessoal.

Se tomarmos uma atividade de um professor, por exemplo, no exercício de uma aula, poderemos perceber o entrelaçamento dessas dimensões: há um aspecto impessoal, o que se exige desse professor pela organização espaço-temporal escolar: controle da turma, não permitir excessos de ruídos, entrada e saída de alunos, "prender" a atenção da turma, transmitir conhecimentos previstos de antemão, falar de determinado modo, utilizar determinados recursos, entre tantos outros. Essa dimensão impessoal é preenchida de um modo singular, não há pura repetição. De algum modo, um professor apodera-se dessa dimensão, imprimindo-Ihe uma marca, uma certa cadência pessoal. Ao mesmo tempo, essa cadência alia-se à do professor na sala ao lado. Como ele faria essa aula? Como ele responderia há uma situação inusitada enfrentada naquela aula? Quais os sentidos que os alunos atribuem ao seu fazer? Nessa direção, a atividade também é interpessoal.

Para Clot, entretanto, essas dimensões não bastam. Entre a atividade "esfriada", prescrita, do como se deve executar determinadas tarefas, e entre o fazer "quente", "do suor na camisa" da atividade viva, e a busca de sentido em um outro para o qual se dirige a tarefa, há uma dimensão transpessoal, atravessada pela história coletiva do trabalho: a atividade pessoal resulta (também) dos recursos mobilizados e transmitidos pelos mais experientes e pela possibilidade de serem transmitidos aos mais novos.

Os modos de subjetivação contemporâneos buscam deixar o sujeito só em face da prescrição do trabalho. Deixando a cada um a definição do agir face à dimensão impessoal da tarefa. Atualmente, o trabalhador é convocado a participar; ser versátil e flexível tornou-se o grande lema. Atente-se aos valores da organização, afirmam os especialistas. É exigida desse trabalhador uma participação intensiva devidamente moldada ao ambiente de trabalho (FONSECA, 2002).

Uma empresa privada do ensino superior, por exemplo, convoca os seus docentes a participar intensamente do ensino, criando uma ferramenta on-line através da qual se estrutura um segundo ambiente de aprendizagem, o antes e o depois da sala de aula, estendendo o tempo hora-aula; e o argumento é de que todo professor planeja a sua aula, e sabe como avaliá-la, tratando-se apenas de tornar essa antes e pós-aula disponível com antecedência para os alunos. Convocação intensiva de trabalho. Nessa mesma empresa, durante a implantação desse sistema de um segundo ambiente de aprendizagem, convoca-se a todos os seus docentes a assumir maior carga horária de trabalho, aqueles que permaneceram após uma drástica redução do quadro de docentes, em nome de uma sustentabilidade, em face de um mercado educacional saturado com a proliferação de vagas. Convocação intensiva. Dimensão impessoal, pois é fato que o segundo ambiente será criado, é fato assumir maior carga horária. Mas essa dimensão não é suficiente para analisar como cada docente redimensiona essa convocação. A que custo decidem como "alimentar", tornar disponível seu planejamento via online, e a convocação a assumir maior carga horária. Cada um responde as essas convocações de modo pessoal.

Ser deixado só face a essa convocação fragiliza esse trabalhador. Para Clot, importa pensar como essas duas dimensões, pessoal e impessoal, precisam ser entrecortadas como suportes para a ação, e, então intervêm a dimensão interpessoal e a transpessoal. Não basta inventar, é necessário que a invenção seja uma estratégia compartilhada por um coletivo. Um coletivo entendido como plano de co-engendramento e de criação, superando a dicotomia e uma lógica que toma os seres e as instituições como dados a priori, sem levar em conta os processos que os engendram. Portanto um coletivo que parte de uma outra lógica - uma lógica atenta ao engendramento, ao processo que antecede, integra e constitui os seres (ESCOSSIA; KASTRUP, 2005).

Os antecedentes da atividade, os componentes que a pré-definem, pré-organizam, não se resumem a uma memória pessoal incorporada por um sujeito em ato. Envolvem também uma segunda memória, objetiva e impessoal, 
que confere uma dada forma à atividade em situação: maneira de comportar-se, maneira de exprimir-se, maneiras de começar uma atividade e acabá-la, maneiras de conduzi-la eficazmente a seu objetivo em contanto com os outros (CLOT, 2006, p. 49).

A essa memória, Clot (2006) nomeia de gênero profissional. Uma memória que precisa ser entendida mais como movimento do que como estado. É processual. Um gênero nunca se encontra acabado, pois engloba a história de fazeres e saberes compartilhados por sujeitos em atividade dirigida em um local de trabalho.

O gênero pode ser entendido como um corpo intermediário entre os sujeitos, um interposto social situado entre eles, por um lado, e entre eles e os objetos de trabalho, por outro. De fato, um gênero sempre vincula entre si os que participam de uma situação, como co-atores que conhecem, compreendem e avaliam essa situação da mesma maneira. A atividade que se realiza num gênero dado tem uma parte explícita e outra parte "sub-entendida". A parte subentendida da atividade é aquilo que os trabalhadores de um meio dado conhecem e vêem, esperam e reconhecem, apreciam ou temem; é o que lhes é comum e que os reúne em condições reais de vida; o que eles sabem que devem fazer graças a uma comunidade avaliações pressupostas, sem que seja necessário re-especificar a tarefa cada vez que ela se apresenta. É como uma "senha" conhecida apenas por aqueles que pertencem ao mesmo horizonte social e profissional. Para serem eficazes, elas são econômicas e, na maioria das vezes, sequer são enunciadas. Entrem na carne dos profissionais, pré-organizam suas operações e seu comportamento (p. 41).

Assim o gênero é obra aberta, que se constitui processualmente, arrasta a memória impessoal, num movimento que é ação transvalorativa posta em execução pelo trabalhador que singulariza o gênero com seu estilo e, ao mesmo tempo, coletiviza o seu saber-fazer. Em uma singularização e coletivização simultâneas emerge um novo ser: o corpo invisível do trabalho.

Como inacabado, processual, o gênero não é um corpus ou uma tábua de leis (CLOT, 2006, p. 47). Ele dá o tom da ação. Permite que um trabalhador não erre sozinho, o gênero Ihes serve de recurso para enfrentar o real. Sem o gênero o sujeito fica só diante de si mesmo (p. 49). Os gêneros profissionais são modos de apreensão de saberes, recurso para evitar errar por si só diante da extensão das tolices possíveis ( $p .47$ ).
Na direção que tomamos esse conceito, consideramos que o gênero nos remete a um plano coletivo de constituição do trabalho, ao qual o trabalhador recorre fazendo frente às variabilidades que se apresentem (CLOT, 2006). É o gênero profissional que permite que a análise dos coletivos de trabalho sejam feitas considerando esse dispositivo aberto de regras impessoais, historicamente construído, ao qual os trabalhadores de uma determinada categoria profissional se refere nas relações de trabaIho, utilizado como forma de agir singularizada, e que conta a história do grupo e a memória impessoal dos ambientes de trabalho.

Coletivo e singular não se desvencilham. Toda atividade de trabalho pode então ser entendida como encontros, encontro de idéias, de experiências, de corpos, num processo complexo de possibilidades que demandam escolhas, inclui valores e é, portanto, atividade de criação. Tem-se assim, o trabalho concebido como obra de arte; uma afirmação da dimensão estética do trabalho.

Mais um atravessamento da perspectiva de Clot com as afirmações deleuzianas, pois esse processo se efetiva num plano micropolítico, conforme conceitua Deleuze e Guattari (1997), e indica um caminho que ao movimentar-se na duração, retira o caráter aparentemente estável das organizações, ampliando suas possibilidades de mobilidade, utilizando esse movimento para modificá-las.

O trabalho e o trabalhador não se reduzem ao que Deleuze e Guattari (1997) chamaram plano molar. O trabalhador enfocado pela Psicologia do Trabalho toma como referência apenas ao plano de organização, do que está constituído. No entanto, um trabalhador molecular, que se constitui no plano micropolítico só pode ser considerado se, além do plano macropolítico, tomarmos como referência também o plano de composição, de constituição das formas. Arriscaríamos dizer que também Clot em suas formulações não se limita ao trabalhador molar, mas acompanha também um trabalhador molecular.

Realçar essa dimensão do trabalho, que afeta e contagia aquele que trabalha, e não se reduz às tarefas prescritas, é falar de um modo de trabalhar que se deixa levar por um devir, isto é, um processo sem programa prévio, explorando e deixando-se contagiar pelo movimento de criação inerente aos processos de trabalho. Para Deleuze e Guattari o homem 
é uma figura molar, uma forma. Sua entrada em devir está na possibilidade de acessar o plano molecular, que só se faz através de devires, ou seja, de velocidades e lentidões que se encontram no plano de composição.

Encontramos neste ponto uma perspectiva que se aproxima da perspectiva da Clínica da Atividade, uma possível intercessão. Pensar o devir do trabalho e do trabalhador em lugar de estudar o trabalho tendo como ponto de chegada e/ou de partida, uma forma trabaIho já dada. Eis aí a inversão radical que se evidencia quando confrontamos tal direção de análise com algumas abordagens no campo da Psicologia do Trabalho. De um plano a outro, as abordagens sobre o trabalho no campo da Psicologia têm adotado, preferencialmente, o modelo da territorialização. As perturbações e instabilidades que têm lugar nos processos de trabalho constituem movimentos de desterritorialização relativa, pois desembocam em compensações e apenas ganham sentido quando constituem um retorno a um equilíbrio. Mesmo quando este equilíbrio é considerado, toma feições de um equilíbrio com ênfase nas formas territorializadas. Em contrapartida, o conceito de devir formulado por Deleuze e Guattari orienta a investigação nos mundos do trabalho para um movimento de desterritorialização, de fuga e desmanchamento das formas. Tomá-lo como ponto de partida em nossas análises no âmbito da Clínica da Atividade, significa deixar de pensar o processo de transformação temporal a partir das formas que dele resultam, ou seja, o processo através do produto, o movimento pela paralisia, a invenção pelo invento. A complexidade dos mundos do trabalho, reafirmamos, advém dessas duas dimensões - molar e molecular - que são irredutíveis uma à outra.

Algumas pesquisas em Psicologia do Trabalho têm priorizado as estruturas ou formas molares que correspondem à territorialização dos processos. Tais formas dotam o trabalho de uma estabilidade relativa, e sem elas o devir, entendido como movimento de desterritorialização, não se efetivaria. É inquestionável a necessidade de que existam formas, pois não há devir senão das formas. No entanto, os processos de trabalho, por sua complexidade, exigem uma psicologia igualmente complexa que, além das formas e estruturas que constituem os mundos do trabalho, acesse 0 devir que, ao invés de pautarem-se apenas no plano de organização, acolha em seu campo de investigação os movimentos involutivos, dissipativos, de desmanchamento das formas constituídas e que evidenciam, de maneira às vezes sutil, a dimensão molecular dos processos de trabalho e seu enraizamento no plano de composição (KASTRUP, 2005). Aqui avançamos na tarefa de 'sujar' a Clínica da Atividade.

O trabalhador constitui a atividade e é constituído por ela, produtor e produto não se divorciam. Territorializações, desterritorializações, reterritorializações. Desmachamento de territórios, constituição de outros. Plano molar, plano molecular. Então, se a dimensão vivida do trabalho é sempre uma criação, uma novidade, não pode ser apreendida inteiramente em palavras e escapa a qualquer tentativa de descrição, uma vez que é da ordem do inesperado, não consegue se expressar em palavras.

\section{Gêneros e estililizações}

De que modo podemos entrelaçar os apontamentos de Clot e Deleuze sobre gênero e estilo? Iremos tatear uma aproximação, sem esquecermos das divergências filosóficas que afastam esses autores. Vejamos alguns exemplos desses processos de estilização.

Clot (2006) nos apresenta a experiência de algumas operárias que aprenderam a consertar as máquinas, mesmo burlando as regras de segurança, de não se aproximar dos painéis de controle, pois isso implicava menos pausa no tempo de produção, e conseqüentemente, aumento de produção, com uma menor dependência da equipe de manutenção. O gênero apóia "os erros coletivos". Para o autor, é como se o gênero dissesse: não é para fazer isso, mas isso ajuda todo mundo (p. 64). Acordos tácitos compartilhados.

Ao relatar o trabalho dos cortadores de pedra parisiense, D. Cru, citado por Clot (2006) aponta para regras fundamentais implícitas na execução das atividades: cada um termina o trabalho que começa; cada um trabalha com suas próprias ferramentas; controle do tempo: nem correr, nem adormecer; cada um pode circular por todo o canteiro. E os novos operários? Cada iniciante "entra num universo de signos que deverá aprender a perceber e a interpretar, às vezes em detrimento de si, sem grande explicação da parte de quem quer que 
seja" (CLOT, 2006, p. 47).

Como já indicamos a flexibilidade do gênero depende diretamente de ser realimentado por novos fazeres de algum modo pessoal. Outro exemplo que nos ajuda a pensar tal a flexibilidade como processual, foi vivido em Vitória/ES. Em uma roleta de um ônibus em Vitória, o trocador, portador de deficiência em uma das mãos, para liberar a roleta prendeu o cartão com um elástico, mantendo o cartão fixo no dorso da mão, apenas aproximando-a do leitor, com isso economizando uma sobrecarga da outra mão, que devido à deficiência, deveria dar o troco e também liberar a roleta. O uso do elástico inicialmente não estava previsto no gênero profissional. Até mesmo porque a introdução dessa tecnologia é recente. Após algum tempo, vários outros trocadores, não deficientes, utilizam o mesmo elástico.

Ao definir as fronteiras móveis do aceitável e inaceitável no trabalho, ao pré-organizar as ações (CLOT, 2006), o gênero convoca a um refazer as regras, exige um estilo pessoal, uma cadência. Uma dupla vida do estilo, fazer o que há de se fazer - impessoal - e ao mesmo tempo imprimir um modo próprio - pessoal. No decurso da ação esses modos impessoais e pessoais são impossíveis de serem delimitados. Quanto mais se conhece o gênero, maior o controle do trabalhador para libertar-se dele, maior a possibilidade de criação estilística.

O estilo retira ou liberta o profissional do gênero não negando este último, não contra ele, mas graças a ele, usando seus recursos, suas variantes, em outros termos por meio de seu desenvolvimento, impelindo-o a renovar-se. O conhecimento dos gêneros profissionais mostra-se, portanto indispensável à psicologia do trabalho e esta deseja ter uma oportunidade de compreender os estilos (CLOT, 2006, p. 41).

A plasticidade dos gêneros depende dos estilos. O inverso também é verdadeiro. O gênero retroage sobre os estilos. Pois o gênero é sempre o mesmo e outro, sempre velho e novo ao mesmo tempo. É assim que ele garante a continuidade do trabalho. Aqui podemos mais uma vez fazer derivar a obra de Yves Clot no que poderíamos nomear com Deleuze como uma "vontade de estilo".

Os mapas de trajetos nos processos de trabalho se constituem por meio de qualidades, substâncias, potências e acontecimentos. Como diz Deleuze (1997): o trajeto confun- de-se não apenas com os que o percorrem, mas, também, com o próprio meio percorrido na medida em que sujeito e meio se coengendram. Viver-pensar o mundo a partir de mapas, e neles criar, desmanchar, construir, transformar, implica paisagens, continentes, cor, movimento, acontecimento. Esta direção ético-política de análise procura a força dos deslocamentos, avalia impasses, relações com outros mapas e situações, entradas e saídas; esta direção de análise trabalha com trajetos e devires, preocupa-se com a mobilização dos deslocamentos em mapas, e os trajetos considerados em sua extensão, intensidade, densidade. $\mathrm{O}$ que oferece sustentação aos trajetos são os devires. Devires e trajetos.

Os trabalhadores fazem, dizem, inventam, estão em devir; exprimem-se de modos singulares nesses trajetos e devires, criam mapas extensivos e intensivos, e o devir na sua viagem relâmpago, não conserva nada de pessoal nem de racional, mas do que esse estado de criação ininterrupta. É este estado que garante ao indivíduo uma possibilidade de estilo, pela qual se orienta, e que lhe permite criar. Desse modo, o estilo é a decomposição e a destruição das formas instituídas de trabaIhar, como destruição de uma língua. A tônica do estilo é o estranhamento.

Em diferentes graus de estranhamento podem surgir dentro da língua uma nova língua, estrangeira e ao mesmo tempo não estrangeira. Devir não é encontrar uma fórmula, mas poder exprimir os imprevistos, instaurar zonas de vizinhanças com não importa o quê, desde que se criem estratégias para tal. Por estilizações, trata-se, então, de se agenciar um trabalho menor, sempre em devir, sempre inacabado.

Criar estilo é criar sintaxe. Sintaxe que passa por um tratamento "deformador, contorcionista", que faz com que a língua na qual se escreve se torne uma língua estrangeira, é levar a linguagem a um tipo de limite. Em Deleuze, portanto, produzir/acoplar um estilo é agenciar uma língua menor, um trabalho menor, que não é prescrição dentro da prescrição e nos permite perceber seus pontos de ruptura e subversão.

Para CLOT (2006), somente no momento em que é perturbado que o gênero é visto ( $p$. 40). Para ele, é preciso cuidar do gênero, pois isso implica na constituição das possibilidades de ação, constituem um espaço comum, para 
além das estratégias individuais. A sua "ausência" ou fragilidade expõem o trabalhador, deixando o só, ou deixando errar sozinho.

A saúde se degrada no ambiente de trabalho sempre que um coletivo profissional torna-se uma coleção de indivíduos expostos ao isolamento. A saúde se degrada, na verdade, quando deixa de haver a ação de civilização do real, a qual um coletivo profissional deve proceder a cada vez que o trabalho, por seus imprevistos, põe esse coletivo a descoberto. Dito de outra forma, a saúde se degrada quando a história do gênero profissional se encontra suspensa. Quando, para dizer ainda de outro modo, a produção coletiva das expectativas genéricas do ofício é posta em sofrimento. Cada um individualmente se encontra então confrontado às más surpresas de uma organização do trabalho que deixa "sem voz" face ao real (CLOT, 2002, s/p).

\section{Autoconfrontação cruzada como metodologia de análise na Clínica da Atividade: cartografias das dimensões não-evidentes da atividade}

As intervenções em situação de trabalho, na direção indicada pela Clínica da Atividade, buscam criar estratégias que viabilizem que o trabalhador seja confrontado com seu trabalho. Busca vialbilizar uma análise minuciosa da atividade e faz do princípio da confrontação um caminho para auxiliar nas complexas análises das situações de trabalho. Com o objetivo de produzir análises de uma atividade laboral, a Clínica da Atividade nos oferece um dispositivo nomeado Experiência em Autoconfrontação Cruzada, lançado pelo lingüista Daniel Faïta. Trata-se de um método de análise da atividade que utiliza a imagem como apoio principal de observações, para criar um quadro que possibilite a um coletivo de trabalho ter sua experiência profissional desenvolvida, por meio de uma prática de co-análise. Conforme Clot e colaboradores (2008) é preciso aumentar o poder de agir dos trabalhadores, sempre presente em situações de trabalho.

A proposta metodológica segue um caminho que perspectiva a direção ético-política indicada na Clínica da Atividade, que indicamos ao longo do artigo, e se constitui das seguintes fases: O filme - A autoconfrontação simples - A autoconfrontação cruzada - Retorno ao meio de trabalho - Apropriação diferenciada do objeto pela equipe de pesquisa (VIEIRA, 2004).
O primeiro momento, a produção de um material em vídeo, demanda uma observação das situações e dos meios profissionais por um determinado período de tempo e, ainda, a constituição de um grupo de análise para participar do processo de co-análise.

O passo seguinte, que se efetiva num processo interativo, pesquisadores e protagonistas se reúnem e assistem à seqüência filmada e editada pelo pesquisador. Nesse momento, demanda-se ao protagonista da atividade emitir comentários e análises a partir da autoconfrontação que estabelece com as imagens do seu fazer.

Em seguida, reúnem-se, num outro momento, o pesquisador, o protagonista que teve seus comentários filmados e mais um membro do coletivo. Este último, trabalhador que participa do mesmo gênero profissional do protagonista das filmagens, assiste às imagens e comentários produzidos por seu colega, na segunda fase (a autoconfrontação simples), emitindo comentários, o que configura uma autoconfrontação cruzada.

Na quarta fase, ocorre a devolução ao meio de trabalho o produzido, que se constitui material relativo às fases de produção, e que tem destinos os mais variados, de forma que se constitua como suporte de possíveis trocas com outros companheiros do mesmo gênero profissional, viabilizando uma formação permanente.

No último momento, o das análises, efetiva-se uma apropriação diferenciada desses materiais produzidos pela equipe de pesquisa. Diferenciada uma vez que são constituídas equipes multiprofissionais e transdisciplinares para analisar um fenômeno que se efetiva no trabalho. Assim, o material produzido é avaliado a partir de vários ângulos e perspectivas, de forma a se fazer uma revisita ao que foi produzido nas fases anteriores.

Esse caminho metodológico foi trilhado pelo grupo de pesquisadores do Núcleo de Estudos e Pesquisas em Subjetividade e Polícias da Universidade Federal do Espírito Santo (NEPESP/UFES) no ano de 2007, numa pesquisa realizada com um grupo de docentes do município da Serra/ES. Tal metodologia surgiu como proposta a partir desse encontro com a abordagem da Clínica da Atividade. Como pensar uma Clínica da Atividade no contexto do trabalho docente?

O trabalho teve início com a constituição de 
um Grupo Ampliado de Pesquisa que denominamos CAP (Comunidade Ampliada de Pesquisa), constituída de pesquisadores do NEPESP/ UFES e de professores da rede municipal de ensino do município da Serra/ES.

A utilização da autoconfrontação cruzada objetivou colocar em análise a atividade do trabalhador docente, de forma a pensar com o professor a atividade que desenvolve na escola.

O primeiro passo foi debater a metodologia proposta com os professores envolvidos no processo investigativo, uma vez que a coanálise é o princípio privilegiado no método em questão, ou seja, a criação de um quadro que permita o desenvolvimento da experiência profissional do coletivo, sempre engajado em um processo permanente de co-análise.

A primeira reunião da CAP (Comunidade Ampliada de Pesquisa) teve, então, como principal objetivo apresentar a proposta da pesquisa. Ainda nesse encontro, houve a indicação da escola e dos professores para participarem dessa etapa do trabalho. O segundo encontro da CAP ocorreu, posteriormente, para escolha das atividades de trabalho a serem filmadas na escola.

A partir da escolha da unidade escolar e dos professores que participariam da pesquisa, foi estabelecido um acordo com o estabelecimento escolhido para viabilizar a filmagem das situações do trabalho docente, conforme pactuado na CAP.

A primeira ação técnica dirigida à filmagem foi a escolha do grupo responsável por sua realização, que foi composto por três pesquisadores do NEPESP e por dois especialistas na gravação em vídeo. Esse grupo visitou previamente o local da filmagem para evitar o confronto com determinados imprevistos no momento da realização da mesma e familiarizar professores e alunos com toda o aparato tecnológico necessário para as filmagens.

O período de gravação das atividades de cada professora teve duração de aproximadamente 50 minutos, período correspondente a uma aula. Num terceiro foi realizada a edição do vídeo, para que fosse exibido para as professoras apenas 20 minutos de cada aula. Essa edição foi validada com o protagonista da atividade filmada.

Foram produzidos quatro vídeos denominados respectivamente de vídeo 1 (material não editado), vídeo 2 (material editado), vídeo
3 (autoconfrontação simples) e vídeo 4 (autoconfrontação cruzada). As autoconfrontações simples e cruzada foram efetivadas no estúdio de gravação do Laboratório de Aprendizagem do Centro de Educação da UFES (LAUFES) buscando-se assegurar as condições propícias à gravação que a partir delas seriam originadas.

Com a autoconfrontação simples, proporcionou-se um encontro de cada professora com o seu próprio trabalho. Deste modo, ao visualizar o que realiza no dia-a-dia na escola, as professoras passam a discutir sobre a atividade desenvolvida, pensar e analisar o que vem sendo realizado e transformar sua própria atividade.

A etapa seguinte foi a realização de um encontro das professoras com o trabalho da colega: produzindo a autoconfrontação cruzada. Nesta, o principal objetivo foi confrontar as posturas e práticas capturadas no vídeo. Junto das professoras estavam mais cinco pesquisadores do NEPESP e o profissional responsável pelo LAUFES.

As professoras, ao analisarem sua atividade, pensam sobre o seu trabalho, discutem com seus pares sobre aquilo que pode ou não gerar adoecimento, pensam sobre de que maneiras é possível minimizar ou mesmo evitar o processo de adoecimento: “Vi que meu trabalho é cansativo e que eu devo a partir desse filme procurar um jeito de melhorar para mim e para eles. Pensar em algo para não me curvar tanto, não falar tanto. Acho que devo mudar a postura um pouco, sentar mais."

A socialização do material filmado sobre as atividades de trabalho ocorreu na própria escola com a presença dos professores dos três turnos de funcionamento, a diretora e os pesquisadores do NEPESP. Esse momento foi importante, pois o grupo da escola validaria ou não o material de pesquisa, antes do mesmo ser divulgado para o restante da rede municipal de ensino.

Algumas semanas depois, o material foi exposto para outros professores e diretores de diversas escolas da rede, num encontro mediado pela Secretaria de Educação do município da Serra. Os presentes expressaram o interesse em terem acesso ao material produzido até o momento pelo grupo de pesquisa, a fim de experimentarem a metodologia utilizada no estudo em suas escolas.

Então, como a clínica da atividade, por meio 
da metodologia da autoconfrontação cruzada, nos ajuda na análise do trabalho docente? O que essa tecnologia viabiliza? A experiência vivida nos mostra que esse caminho metodológico, ao não visar a uma simples restituição dos dados construídos no curso da investigação, produz a experiência. A análise do trabaIho realizada confere um valor à experiência descrita e recusa a dicotomia entre posição cognitivista e subjetivista na análise da atividade: o caminho perseguido é o do intercâmbio entre os diferentes sujeitos que praticam a educação, que mobiliza a atividade e inscreve os traços dessa mudança numa história pessoal que tem seu próprio curso.

Tal caminho busca mais do que conhecer, analisar ou denunciar as formas de dominação e sofrimento existentes nas escolas, e construir alianças com as possibilidades que os trabalhadores têm de criar e recriar suas próprias relações com sua atividade profissional. Visa a levar o trabalhador à posição de observador de seu próprio trabalho e o objetivo mais importante é produzir interlocução, possibilitar que o trabalhador se surpreenda com aquilo que, por muito familiar, já passava despercebido e favorecer que os diferentes modos possíveis de enfrentamento do real da atividade sejam postos em debate, desenvolvendo o gênero e ampliando suas possibilidades como instrumento para a ação de cada um (OSÓRIO, 2007).

Assim, a autoconfrontação cruzada possibilitou:

- Deslocar o trabalhador-docente para o lugar de observador e analista do seu trabalho, na medida em que o pesquisador assessora e facilita o debate.

- Fazer um debate sobre uma marca do trabalho produzida coletivamente, fruto do diálogo que enriquece o gênero profissional; o debate sobre a atividade, evita a personalização e o julgamento sobre as escolhas individuais.

- Favorecer deslocamentos, elaborações e re-elaborações, a partir das análises que se produzem no processo.

Temos observado, na maior parte das escolas, gêneros profissionais enfraquecidos, na medida em que as exigências aumentam e reduzem-se os recursos existentes para fazer frente a essas exigências. Esse é um desafio que se coloca para análises do trabalho que tem como princípio ético-político que os humanos são plásticos, dialógicos e inventivos e, como nos aponta a pesquisa realizada, a verbalização da atividade tem sido uma excelente estratégia nessa direção.

\section{Clínica da Atividade pela via deleuziana: potência analítica}

Como tentamos indicar ao longo do texto, consideramos que a Clínica da Atividade, com suas ferramentas conceituais e tecnológicas, auxilia na cartografia do trabalho por apontar questões centrais (ou de borda): o trabalho é da ordem da vida, só podendo ser analisado junto com os próprios trabalhadores, e trabaIhar nunca é da ordem da mera repetição, nem mesmo da mera invenção individual. Trabalhar é explodir com os territórios dualizados: individual, coletivo, pessoal, social, eu e outros.

Nas intercessões com Deleuze o trabalho necessariamente precisa ser analisado como da ordem da vida, que rompe com os mecanismos meramente prescritivos. Ao contrário de uma perspectiva molar a cerca dos fazeres humanos, inquieta-nos interrogar: como o trabalho se efetiva como uma forma de enfrentamento, de resistência, de devir? Como, ao trabalhar, o trabalhador inventa outros modos de existência? Que encontros são potencializados? Que afetos e perceptos são disparados? De que maneira produz mil arranjos não antevistos? O trabalho pode ser vivido como um trabalho (com artigo indefinido)?

Essa insistência visa a um objetivo diferente do reconhecimento de um fato. Parece realmente que a ausência ou enfraquecimento de um trabalho de organização promovido e mantido por um coletivo esteja com freqüência na origem dos desregramentos da ação individual mediante os quais é indicada a perda de sentido e da eficácia do trabalho [...] o trabalho só preenche sua função psicológica para o sujeito se the permite entrar num mundo social cujas regras sejam tais que ele possa ater-se a elas. Sem lei comum para dar-lhes um corpo vivo, o trabalho deixa cada um de nós diante de nós mesmos (CLOT, 2006, p. 18).

Analisar o trabalho, portanto, é focar não somente as práticas instituídas, mas afirmar a potência instituinte de toda atividade laboral, o que nos remete a um posicionamento ético, uma implicação nas relações de poder em que nos movemos para que não sejamos seduzidos pelas tentações da dessimetria, nas quais 
a análise do trabalho passa a ser dominação e controle (MAIA, 2006).

Buscando apreender as relações de forças que nos constituem como sujeitos do conhecimento interessados no poder-saber do trabalho e no poder-saber do trabalhador, empenhamo-nos em não alijar os trabalhadores do saber sobre seu trabalho, silenciando-os pelos saberes disciplinares-acadêmicos e ficando ensurdecidas pelos especialismos. Mas é bom afirmar: ao questionar os especialismos, não estamos abdicando dos regimes de saber disciplinares, que se constituíram e se constituem ao longo da história, mas, apenas colocando em questão a utilização de um critério de verdade que se perpetua e que, quando utilizado, invalida a experiência daquele que vive e, ao viver, se 'suja' ao fazer seu trabalho.
Essa direção ética, que recusa os especialismos que buscam docilizar o outro, afirma o outro como legítimo outro que não é passivo por que vivo, e cuja resistência se faz sentir nos encontros, tensionando-os, tornando os ambientes de trabalho um plano em construção constante, no qual o estado de sujeição de qualquer um dos pólos desse processo não se completa inteiramente, uma vez que este outro resiste - na dupla acepção da palavra, ou seja, como recusa e como invenção - e se impõe, com seu saber-poder, mesmo quando se tenta afirmar uma relação dessimétrica. 0 sonho taylorista não se efetivou, nem se efetivará, já que o próprio do vivo é a liberdade, como uma forma permanente de interrogar o que estamos fazendo de nós mesmos, afirmando o que estamos em via de diferir.

\section{Referências}

ATHAYDE, M. Psicologia e trabalho: que relações? In: JACÓ-VILELA, A. M.; MANCEBO, D. (Orgs.). Psicologia social: abordagens sócio-históricas e desafios contemporâneos. Rio de Janeiro: EDUERJ, 1999. p. 195-200.

ATHAYDE, M.; FIGUEIREDO, M. Coletivos de trabalho e componentes subjetivos da confiabilidade em sistemas sociotécnicos complexos: considerações a partir da situação de trabalho em mergulho profundo na Bacia de Campos (RJ). In: FIGUEIREDO, M.; ATHAYDE, M.; BRITO, J.; ALVAREZ, D. (Orgs.). Labirintos do trabalho. Rio de Janeiro: DP\&A, 2004. p. 241-275.

CLOT, Y. Clínica do trabalho, clínica do real. Tradução para fins didáticos: Kátia Santorum e Suyanna Linhales Barker. Revisão: Cláudia Osório. Le J ournal des Psyychologues, Paris, n. 185, mars 2001.

CLOT, Y. A função psicológica do trabalho. Petrópolis: Vozes, 2006.

CLOT, Y. Clínica da atividade. Curso ministrado na Universidade Federal Fluminense, ago. 2007. Mimeografado.

CLOT, Y.; FAÏTA, D.; FERNANDEZ, G.; SCHELLER, L. Les entretiens en a utoconfrontation croisée: un e méthode en clinique de l'activité. Pistes: réflexion sur la pratique, Paris, v. 2, n. 3, p. 1-7, 2000. Disponível em: <http://pettnt/v2n1/articles/v2n1a3.htm>. Acesso em: 04 ago. 2008.

CLOT, Y.; LEPLAT, J. La méthode clinique en ergonomie et em psychologie du travail. Le Travail Humain, Paris, v. 68, n. 4, p. 289-316, 2005.

COIMBRA, C. Quando a clínica se encontra com a política. Revista do Departamento de Psicologia - UFF, Niterói, v. 14, n. 2, 2002.

DELEUZE, G. Clínica e crítica. Rio de Janeiro: Ed. 34, 1997.

DELEUZE, G. Foucault. São Paulo: Brasiliense, 2005. 
DELEUZE, G.; GUATTARI, F. Mil platôs: capitalismo e esquizofrenia. Rio de Janeiro: Ed. 34, 1995. v. 2.

FONSECA, T. M. G. Modos de trabalhar, modos de subjetivar no contemporâneo. Revista do Departamento de Psicologia - UFF, Niterói, v. 14, n. 2, 2002.

LOURAU, R. Les lapsus des intellectuels. Paris: Privat, 1981.

ESCOSSIA, L. da; KASTRUP, V. A concept of collective for overcoming the individual-society dichotomy. Psicologia em Estudo, Maringá, v. 10, n. 2, 2005. Disponível em:<http://www.scielo.br/scielo.php?script=sci_art text\&pid=S14133722005000200017\&lng=en\&nrm=iso>. Acesso em: 21 nov. 2007.

MAIA, M. A. B. O corpo invisível do trabalho - cartografia dos processos de trabalho em saúde. 2006. Dissertação (Mestrado em Psicologia) - Universidade Federal Fluminense, Niterói, 2006.

OSÓRIO, C. Trabalho e perspectivas clínicas. In: COLÓQUIO INTERNACIONAL DE PSICOSSOCIOLOGIA E SOCIOLOGIA CLÍNICA, 11., 2007, Belo Horizonte. Anais... Belo Horizonte: Universidade Federal de Minas Gerais, 2007.

SELLIGMAN-SILVA, E. Desgaste mental no trabalho dominado. Rio de Janeiro: Cortez, 1994.

VIEIRA, M. A. M. Autoconfrontação e análise da atividade. In: FIGUEIREDO, M. et al. (Orgs.). Labirintos do trabalho: interrogações e olhares sobre o trabalho vivo. Rio de Janeiro: DP\&A, 2004. p. 214-237.

Recebido em fevereiro de 2008

Aceito para publicação em abril de 2008

Maria Elizabeth Barros de Barros

Universidade Federal do Espírito Santo, Departamento de Psicologia.

betebarros@uol.com.br

\section{Ana Paula Louzada}

Faculdade Salesiana de Vitória. Departamento de Psicologia. 